\title{
Beyond idiopathic pulmonary fibrosis: the world of progressive-fibrosing interstitial lung disease
}

\author{
Sergio Harari
}

Affiliation: U.O. di Pneumologia e Terapia Semi-Intensiva Respiratoria, Servizio di Fisiopatologia Respiratoria e Emodinamica Polmonare, Ospedale San Giuseppe, MultiMedica IRCCS, Milan, Italy.

Correspondence: Sergio Harari, U.O. di Pneumologia e Terapia Semi-Intensiva Respiratoria, Servizio di Fisiopatologia Respiratoria ed Emodinamica Polmonare, Ospedale San Giuseppe, MultiMedica IRCCS, via San Vittore 12, 20123 Milan, Italy. E-mail: shararidilpolmone.it

@ERSpublications

Beyond IPF: the world of PF-ILD http://ow.ly/zZZ430mYeaE

Cite this article as: Harari S. Beyond idiopathic pulmonary fibrosis: the world of progressive-fibrosing interstitial lung disease. Eur Respir Rev 2018; 27: 180110 [https://doi.org/10.1183/16000617.0110-2018].

In this issue, the European Respiratory Review publishes a series of articles on fibrosing interstitial lung diseases (ILDs) that present with a progressive phenotype. Progressive-fibrosing ILD (PF-ILD) is a terminology recently used to describe these patients. In addition to patients with idiopathic pulmonary fibrosis (IPF), there is a large and more diverse group of patients who develop PF-ILD. These patients are suffering from a disorder that shares a number of clinical features with IPF including: increasing respiratory symptoms; decline of the physiological functions; limited response to immunomodulatory therapy; premature mortality; and significantly impaired quality of life. These articles raise the awareness of these PF-ILDs and review our current understanding of their clinical behaviour and management. OLSON et al. [1] report on the present status of epidemiology, with an overview on the incidence and prevalence of progressive-fibrosing lung disease. The presentation, diagnosis and clinical course of the spectrum of PF-ILD is well described by CotTin et al. [2], while the role of imaging is analysed in depth by WALSH et al. [3]. A detailed analysis of the key role, burden, management and definition of acute exacerbations in PF-ILD is provided by KolB et al. [4]. Finally, RicheLDI et al. [5] provide an interesting overview on the currently available management options in PF-ILD including possible future alternatives, while SwIGRIs et al. [6] present a review on the evaluation and monitoring of the currently available patient-reported outcome instruments and Holtze et al. [7] discusses the problems related to the healthcare burden of these diseases.

Two further reviewes on ILD are published in this issue of the European Respiratory Review, in addition to those discussed above. The first in on a subject that is poorly investigated and understood; the mortality risk factors and mortality rates of these patients in intensive care units [8]. The second one is a systematic review on the benefits of chest magnetic resonance imaging in ILD [9].

As you may well understand, this set of contributions was provided by worldwide known authors who are leading experts in this field and who offer a comprehensive and rounded view on these conditions, which are closely related to IPF and that may present differences in their behaviour and the clinical approaches. I do believe that these overviews will represent for all of us an important point of reference for a pathology whose knowledge is rapidly evolving and calling for visions and integrated clinical approaches, such as those that are offered here.

Provenance: submitted article, peer reviewed.

Received: Dec 072018 | Accepted after revision: Dec 112018

Copyright OERS 2018. ERR articles are open access and distributed under the terms of the Creative Commons Attribution Non-Commercial Licence 4.0. 
Conflict of interest: S. Harari reports grants and personal fees from Roche, Actelion and Boehringer Ingelheim, outside the submitted work. In addition to being an investigator in trials involving these companies, relationships include lectures and membership of scientific advisory boards and grant for research.

\section{References}

1 Olson AL, Gifford AH, Inase N, et al. Epidemiology of idiopathic pulmonary fibrosis and interstitial lung diseases at risk of a progressive-fibrosing phenotype. Eur Respir Rev 2018; 27: 180077.

2 Cottin V, Hirani NA, Hotchkin DL, et al. Presentation, diagnosis and clinical course of the spectrum of progressive-fibrosing interstitial lung diseases. Eur Respir Rev 2018; 27: 180076

3 Walsh S, Devaraj A, Enghelmayer JI, et al. Role of imaging in progressive-fibrosing interstitial lung diseases. Eur Respir Rev 2018; 27: 180073.

4 Kolb M, Bondue B, Pesci A, et al. Acute exacerbations of progressive-fibrosing interstitial lung diseases. Eur Respir Rev 2018; 27: 180071.

5 Richeldi L, Varone F, Bergna M, et al. Pharmacological management of progressive-fibrosing interstitial lung diseases: a review of the current evidence. Eur Respir Rev 2018; 27: 180074.

6 Swigris J, Brown KK, Abdulqawi R, et al. Patients' perceptions and patient-reported outcomes in progressive-fibrosing interstitial lung diseases. Eur Respir Rev 2018; 27: 180075.

7 Holtze C, Flaherty K, Kreuter M, et al. Healthcare utilisation and costs in the diagnosis and treatment of progressive-fibrosing interstitial lung diseases. Eur Respir Rev 2018; 27: 180078.

8 Huapaya JA, Wilfong EM, Harden CT, et al. Risk factors for mortality and mortality rates in interstitial lung disease patients in the intensive care unit. Eur Respir Rev 2018; 27: 180061.

9 van der Wall SJ, van der Pol LM, Ende-Verhaar YM, et al. Fatal recurrent VTE after anticoagulant treatment for unprovoked VTE: a systematic review. Eur Respir Rev 2018; 27: 180094. 